\title{
Trabalhos de campo na disciplina de Geologia Introdutória: a saída autônoma e seu papel didático
}

\author{
Adalberto Scortegagna \\ Departamento de Geografia da Faculdade de \\ Ciências Humanas e Sociais de Curitiba - FACIAUSO e \\ Centro de Estudos e Pesquisas (CEP), Colégio Bom Jesus \\ ascort@uol.com.br \\ Oscar Braz Mendonza Negrão \\ Departamento de Geociências Aplicadas ao Ensino \\ Instituto de Geociências - UNICAMP \\ oscar@ige.unicamp.br
}

\footnotetext{
Este documento deve ser referido como segue: Scortegagna, A.; Negrão, O.B.M. 2005. Trabalhos de campo na disciplina de Geologia Introdutória: a saída autônoma e seu papel didático.Terræ Didatica, 1(1):36-43. $<$ http://

www.ige.unicamp.br/ terraedidatica/>
}

RESUMO

São relatados diversos tipos de trabalhos de campo e seus papéis didáticos, relacionando-os com a disciplina de Geologia Introdutória aplicada ao curso de Geografia. Os tipos de trabalhos de campo relatados são: as saídas de campo Ilustrativa, Indutiva, Motivadora, Treinadora e Investigativa. Sugere-se uma nova proposta de trabalho de campo, a saída de campo Autônoma, na qual os alunos realizam trabalhos sem a presença do professor em campo. Esta nova proposta de trabalho favorece atividades investigativas constantes ao longo da disciplina, pois a partir dos temas que vão sendo abordados em sala de aula, os alunos têm a possibilidade de fazer a inter-relação entre a teoria e sua aplicação no cotidiano. Outro aspecto importante refere-se ao fato de permitir a participação total da turma, pois os horários de ida ao campo são agendados pelos próprios grupos de estudo, em especial turmas do período noturno, que tradicionalmente participam menos de saídas de campo realizadas em finais de semana.

\footnotetext{
ABSTRACT The article describes diverse types of field works and its didactic roles, relating them with a discipline of applied Introductory Geology for the course of Geography. The types of fieldworks are: the Illustrative, Inductive field, Motivator, Trainer and Investigative. It is here suggested types a new proposal of fieldwork, the Authonomous field activity, when pupils carry through works without the presence of the professor in the field. This new work proposal favors to continuous investigative activities a long the disciplines, therefore from the subjects that are approached on classroom, pupils have the possibility of make relationships between the theory and its application in the daily one. Another important aspect is to allow the total participation of the group, therefore the schedules of field trips are set by appointments from the proper study groups. This is of a special interest for groups of the nocturnal period, that shows less participation in fieldwork on weekends.
} 


\section{Introdução}

Os trabalhos de campo são de fundamental importância no aprendizado de Geologia e Geografia. É no campo que o aluno poderá perceber e apreender os vários aspectos que envolvem o seu estudo, tanto naturais quanto sociais.

Vários autores desenvolveram trabalhos valorizando as atividades de campo no aprendizado do aluno, destacando-se Brañas et al (1981), Anguita \& Ancochea (1981), Paschoale (1984), Spencer (1990), Compiani (1991), Brusi (1992), Compiani \& Carneiro (1993), Morcillo et al. (1998), Fantinel (2000), entre outros.

"As atividades de campo, eminentemente práticas e investigativas, devem direcionar o aluno para a aquisição de uma metodologia de campo, que propicie um conhecimento globalizado de uma área de estudo e aquisição de uma visão abrangente da Geologia, não devendo consistir em uma mera exposição de processos e fenômenos geológicos". Compiani (1991:4)

Morcillo et al. (1998) acredita que os trabalhos de campo são especiais no ensino das ciências naturais, algo aparentemente impossível de suprir com atividades em sala de aula e no laboratório.

Paschoale (1984) destaca o campo como "cenário de geração, problematização e crítica do conhecimento, onde o conflito entre o real e as idéias ocorre com toda a intensidade". Sem dúvida, os trabalhos de campo em Geografia e Geologia são imprescindíveis, pois permitem ao aluno se posicionar perante o saber teórico e a realidade vigente, desmitificando a ciência e construindo um saber mais próximo do seu cotidiano.

Particularmente em Geografia, as práticas de campo apresentam infinitas possibilidades de pesquisa e investigação, pois é na ciência geográfica que aspectos físicos e humanos se tornam objetos de estudo concomitantes.

Os trabalhos de campo são fundamentais para o aluno observar e interpretar a região onde vive e trabalha, produzindo seu próprio conhecimento, adquirindo competência para tornar-se um agente transformador em seu meio. Compiani (1991) destaca que, por meio das observações e interpretações da região, o aluno mostra-se capaz de formular noções da geologia local, suas interações com o meio ambiente e problemas sociais. $\mathrm{O}$ aluno passa a ser um investigador e, no futuro, poderá estimular seus próprios alunos à prática da investigação.

\section{Classificação de trabalhos de campo}

Compiani \& Carneiro (1993:90) classificam as excursões geológicas ${ }^{1}$, de acordo com seu papel didático. Os autores definem os papéis didáticos como "funções que determinada atividade assume dentro do processo de ensino-aprendizagem, decididas de maneira deliberada ou não, que exercem algum significado para o alcance de objetivos didáticos".

Os parâmetros utilizados pelos autores para essa classificação são os seguintes:

- objetivos pretendidos

- visão de ensino presente no processo didático;

- emprego/questionamento dos modelos científicos existentes;

- método de ensino, e relação docente-aluno;

- lógica predominante no processo de aprendizagem.

Esses parâmetros são por eles definidos conforme segue:

- Objetivos pretendidos: O pequeno diagrama explicativo na Figura 1 (Objetivo das Atividades) busca sintetizar os principais objetivos das práticas de campo. Apresenta os objetivos gerais dessas atividades, focalizando a participação e o desempenho específico dos alunos. Nas excursões, tais objetivos podem ser explicitados conforme segue:

- Aproveitar os conhecimentos geológicos prévios de cada um.

- Adquirir representações e/ou exemplificar feições ou fenômenos da natureza.

- Sugerir problemas e permitir uma primeira elaboração de dúvidas e questões.

- Desenvolver e exercitar habilidades.

- Estruturar hipóteses, resolver problemas e elaborar sínteses.

- Desenvolver novas atitudes e valores.

A influência exercida pelos objetivos, nos diferentes tipos de excursão, pode ser analisada segundo as categorias "ausente", "fraca", "forte" e "muito forte", compondo as associações gerais assinaladas na Figura 1.

1 Compiani \& Carneiro usam a expressão excursões geológicas (EG), neste artigo substituído por trabalhos, atividades ou saídas de campo, sem prejuízo do significado proposto por tais autores. 
- Visão de ensino: Em geral, qualquer discussão sobre a produção de conhecimento, vista sob perspectiva educacional, pode ser estruturada a partir de dois enfoques: o informativo e o formativo. O ensino tradicional, de modo geral, é mecânico e pouco eficiente quanto a proporcionar uma reflexão independente e autônoma dos alunos na aprendizagem; predomina um trabalho informativo, ou seja, que prioriza a aquisição e memorização dos dados e informações. Em contrapartida, o ensino formativo é interativo e crítico, propiciando uma participação ativa do aluno na aprendizagem. Em Geologia, o ensino informativo, mais tradicional, busca oferecer um repertório de informações sobre conceitos (minerais, rochas, fósseis, estruturas, etc.), descrições e explicações sobre processos, além de pretender treinar habilidades e técnicas importantes para a prática científica do geólogo. O segundo, formativo, preocupa-se com o método de produção científica historicamente contextualizada; o repertório científico é visto como algo em permanente construção a partir da interação sujeito/meio (objeto de investigação).

\section{- Emprego e/ou questionamento de mode-}

los científicos: O questionamento ou a preservação dos modelos científicos existentes à época em que os trabalhos de campo são realizados é um critério importante, embora muitas vezes a organização de uma excursão não leve isso em conta, talvez pelo limitado alcance dos objetivos das atividades.

Para uma excursão, a sua independência face aos modelos existentes significa que estes não interferem no processo didático pretendido. Outras excursões limitam-se a recuperá-los, transmiti-los e valorizá-los, de modo que estes são aceitos e preservados, em graus variáveis. Finalmente, existem excursões em que os modelos são aceitos, mas questionados durante o processo de aprendizagem, à medida que surgem problemas e dúvidas que remetem para novas e novas investigações bibliográficas, de campo ou de laboratório. O resultado final do processo pode ser tanto a reformulação como a própria aceitação dos conteúdos em foco, porém num outro nível de compreensão das teorias e modelos existentes.

- Método de ensino e relação docente-aluno: Para cada tipo de excursão, os métodos de ensino e a interdependência professor-aluno
(P/A) devem ser analisados. Assim, os métodos de ensino são caracterizados como dirigidos, semidirigidos e não-dirigidos (Brusi 1992) e a relação $\mathrm{P} / \mathrm{A}$ pode ser centrada no professor, centrada no aluno ou de equilíbrio. A condição de equilíbrio entre o docente e o aluno, embora desejável em alguns casos, sofre deslocamentos para um lado ou outro, dependendo dos objetivos didáticos pré-estabelecidos. A centralização do processo de ensino-aprendizagem, desse modo, compõe uma forma válida de classificar as excursões geológicas.

Em uma excursão dirigida, o protagonista central é o professor: tudo se desenrola segundo as idéias deste e os alunos desempenham um papel orientado, no sentido de redescobrir paulatinamente os conceitos e fatos que o professor pretendia enfatizar desde o início. Seu contraponto é a atividade nãodirigida, na qual os alunos são estimulados a uma investigação autônoma: são desconhecidos, a priori, os resultados que podem ser atingidos. $\mathrm{Na}$ condição de equilíbrio, o aluno é protagonista da redescoberta, orientado pelo professor, mas este não define previamente as conclusões que devam ser obtidas.

- Lógica predominante no processo: $\mathrm{O}$ título genérico de lógica da ciência engloba referenciais de conteúdo e esquemas de raciocínio, inclusive operações mentais complexas, que se fazem presentes no chamado método científico. Normalmente predominam operações imbuídas da lógica científica, nas excursões que buscam enfatizar aspectos teóricos, habilitar o estudante ao uso de certas técnicas, transmitir conceitos ou simplesmente ilustrar feições citadas em salas de aula.

A lógica do aprendiz pode se constituir em algo muito diverso, já que tem origem na postura natural do estudante frente a situações inéditas. É admitida a aplicação de uma forma de raciocínio própria, sem censurar eventuais imperfeições que a lógica científica poderia identificar. Nesse caso, outros fatores interferem na elaboração do conhecimento, e o alcance das metas didáticas dependerá da influência dos demais fatores acima referidos.

A partir destes parâmetros, Compiani \& Carneiro (1993) classificam as excursões geológicas de acordo com seu papel didático em atividades de campo Ilustrativas, Indutivas, Motivadoras, Treinadoras e Investigativas. Os autores definem em detalhe cada uma delas. 


\begin{tabular}{|c|c|c|c|c|c|}
\hline $\begin{array}{l}\text { CAIEGORIA } \\
\text { PAPE }\end{array}$ & $\begin{array}{l}\text { OBJEIVO DAS } \\
\text { ATIVIDADES }\end{array}$ & $\begin{array}{l}\text { VISÃO DE } \\
\text { ENSINO }\end{array}$ & $\begin{array}{l}\text { MODELOS } \\
\text { CIENIIIFICOS } \\
\text { EXISIENIES }\end{array}$ & $\begin{array}{c}\text { RELACHÃO } \\
\text { DE ENSINO/ } \\
\text { APRENDIZAREM }\end{array}$ & $\begin{array}{c}\text { LÓGCA } \\
\text { PREDOMINANTE }\end{array}$ \\
\hline Ilustrativa & & Informativa & $\begin{array}{l}\text { São aceitos e } \\
\text { preservados }\end{array}$ & $\begin{array}{c}\text { Professor } \\
\text { é o centro } \\
\text { Ensino dirigido }\end{array}$ & Da ciência \\
\hline Indutiva & & $\begin{array}{l}\text { Formativa/ } \\
\text { Informativa }\end{array}$ & $\begin{array}{l}\text { São aceitos e } \\
\text { preservados }\end{array}$ & $\begin{array}{l}\text { Aluno é o centro } \\
\text { Ensino dirigido/ } \\
\text { semi-dirigido }\end{array}$ & $\begin{array}{l}\text { Da ciência e } \\
\text { do aprendiz }\end{array}$ \\
\hline Motivadora & & Formativa & $\begin{array}{l}\text { São aceitos e } \\
\text { preservados, em } \\
\text { grau variável }\end{array}$ & $\begin{array}{c}\text { Aluno é o centro } \\
\text { Ensino } \\
\text { não-dirigido }\end{array}$ & Do aprendiz \\
\hline Treinadora & & $\begin{array}{l}\text { Formativa/ } \\
\text { Informativa }\end{array}$ & $\begin{array}{l}\text { São aceitos e } \\
\text { preservados }\end{array}$ & $\begin{array}{c}\text { Equilíbrio } \\
\text { Ensino } \\
\text { semi-dirigido }\end{array}$ & $\begin{array}{l}\text { Da ciência e } \\
\text { às vezes } \\
\text { do aprendiz }\end{array}$ \\
\hline Investigativa & & Formativa & $\begin{array}{l}\text { São aceitos, mas } \\
\text { questionados }\end{array}$ & $\begin{array}{c}\text { Aluno é o centro } \\
\text { Ensino } \\
\text { não-dirigido }\end{array}$ & $\begin{array}{l}\text { Da ciência e } \\
\text { do aprendiz }\end{array}$ \\
\hline Autônoma & & Formativa & $\begin{array}{l}\text { São aceitos, mas } \\
\text { questionados }\end{array}$ & $\begin{array}{c}\text { Aluno é o centro } \\
\text { Ensino } \\
\text { não-dirigido }\end{array}$ & $\begin{array}{l}\text { Da ciência e } \\
\text { do aprendiz }\end{array}$ \\
\hline
\end{tabular}

\begin{tabular}{|c|c|}
\hline \multicolumn{2}{|c|}{ OBJEIJVOS DAS AIIVIDADES } \\
\hline $\begin{array}{c}\text { Aproveitar os } \\
\text { conhecimentos } \\
\text { geológicos prévios }\end{array}$ & $\begin{array}{c}\text { Reconhecer feições } \\
\text { e fenômenos } \\
\text { da natureza }\end{array}$ \\
\hline $\begin{array}{c}\text { Elaborar dúvidas } \\
\text { e questões }\end{array}$ & $\begin{array}{l}\text { Desenvolver e } \\
\text { exercitar } \\
\text { habilidades }\end{array}$ \\
\hline $\begin{array}{l}\text { Estruturar hipóteses/ } \\
\text { sínteses e criar } \\
\text { conhecimento }\end{array}$ & $\begin{array}{l}\text { Desenvolver } \\
\text { atitudes e } \\
\text { valores }\end{array}$ \\
\hline
\end{tabular}

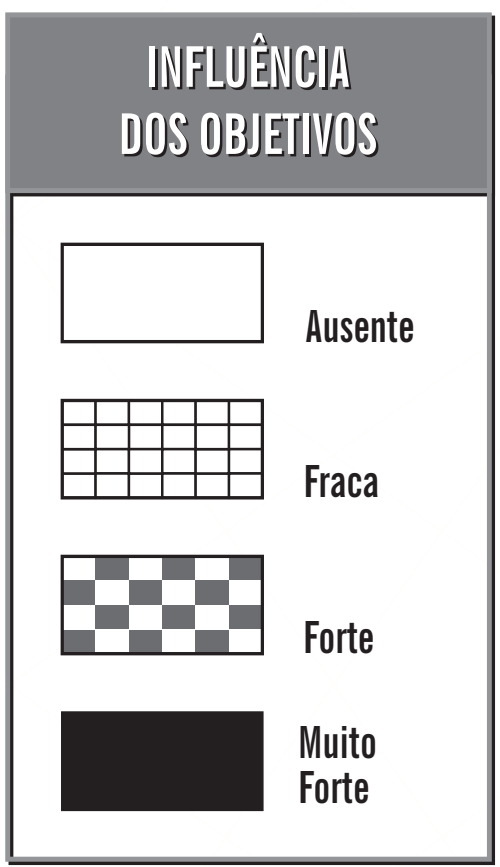

Figura 1 - Objetivos de ensino/aprendizagem nas excursões geológicas 
- Atividade de Campo Ilustrativa: é considerada a mais tradicional das saídas de campo, pois reafirma o conhecimento como produto acabado. Serve para mostrar ou reforçar os conceitos já vistos em sala de aula. É centrada no professor que se utiliza da lógica da ciência para reforçar o conteúdo no campo. O aluno faz o papel do espectador com a caderneta de campo repleta de anotações repassadas pelo professor.

- Atividade de Campo Indutiva: este tipo de saída de campo visa "guiar seqüencialmente os processos de observação e interpretação, para que os alunos resolvam um problema dado". O papel do professor é de conduzir os alunos ou fazer com que eles sigam um determinado roteiro de atividades, geralmente acompanhado por questionário envolvendo questões teóricas com conceitos previamente estabelecidos. O ensino é dirigido, podendo chegar a semidirigido, mas é delimitado pelo professor que define o ritmo dos trabalhos. Segundo os autores "o processo de aprendizagem valoriza os métodos científicos e o raciocínio lógico dos alunos, sem preocupar-se com os conhecimentos geológicos prévios".

- Atividade de Campo Motivadora: Este tipo de saída de campo tem como objetivo despertar o interesse dos alunos para um dado problema ou aspecto a ser estudado. Este tipo de trabalho é, geralmente, realizado com alunos desprovidos de conhecimentos geológicos anteriores, porque valorizam-se aspectos mais genéricos, como a paisagem, o senso comum e a afetividade com o meio. O objetivo é despertar a curiosidade e o interesse do aluno para a disciplina ou curso. A saída de campo é centrada no aluno, valorizando a experiência de cada um e os seus questionamentos.

- Atividade de Campo Treinadora: Este tipo de saída de campo visa treinar habilidades, geralmente com o uso de aparelhos, instrumentos ou aparatos científicos. Exige conhecimentos prévios por parte do aluno que fará anotações, medições ou coleta de amostras. As atividades são direcionadas pelo professor, cabendo ao aluno seguir as recomendações e treinar a técnica ou procedimento.

- Atividade de Campo Investigativa: Esse tipo de saída de campo propicia ao aluno resolver determinados problemas no campo. Os alunos podem elaborar hipóteses a ser pesquisadas; estruturar a sequiência de observação e interpretação; decidir as estratégias para validá-las, inclusive avaliando a necessidade de recorrer à literatura; discutir entre si as reflexões e conclusões.

$\mathrm{Na}$ atividade de campo investigativa o papel do professor é o de um orientador que resolve as dúvidas dos alunos quando solicitado, além de incentivá-los, dando o suporte necessário para que os mesmos não se dispersem no assunto a ser trabalhado. O professor pode propor um problema para ser solucionado o que direciona a atenção dos alunos para o conteúdo. A saída é centrada no aluno e valoriza seus conhecimentos prévios, não se importando muito com a lógica da ciência, pois aqui o professor considera o aluno capaz de desenvolver habilidades no campo teórico.

Newerla (1997) concebe a saída "Treinadora" como uma variante do trabalho de campo Indutivo, ao assinalar que são raras as atividades de campo dedicadas exclusivamente ao treino e ao exercício de habilidades. Não obstante, nos cursos de Geografia há algumas saídas exclusivamente treinadoras, como por exemplo nas disciplinas de Cartografia e Topografia, em que os alunos dirigem-se ao campo exclusivamente para coletar dados a serem, posteriormente, trabalhados em sala de aula.

Morcillo et al. (1998) levanta questões sobre as características distintivas do trabalho de campo, no ensino das ciências naturais, e sobre a importância e necessidade do campo. Afirma que essas questões são pouco discutidas e que as propostas de trabalho de campo dos professores estão muito ligadas à sua própria experiência autodidata.

Propõe-se aqui outro tipo de trabalho de campo, a saída de campo autônoma.

Antes de descrever a saída autônoma, cabe ressaltar um tipo de atividade de campo comum nos cursos de Geografia, não incluída na classificação porque não apresenta objetivos educacionais claros. São excursões cujo principal objetivo é conhecer uma determinada região, possivelmente ainda não visitada pela maioria dos alunos e professores. Não há o comprometimento dos professores em acompanhar os alunos, sendo, muitas vezes, optativa a participação destes. O trabalho de campo, neste caso, fica em segundo plano. Este tipo de saída apresenta um aspecto motivador, que não é, porém, o principal objetivo do professor, uma vez que tais excursões realizam-se geralmente no final do ano letivo, tendo caráter finalístico. Scortegagna (2001) constatou este tipo de saída de campo em uma instituição de ensino no Estado do Paraná. 


\section{Saída de campo autônoma}

Esta saída objetiva despertar no aluno o seu espírito investigativo e prepará-lo para a sua realidade profissional futura. É realizada, preferencialmente, na região onde os alunos se encontram, em áreas escolhidas por eles e sem a presença do professor. A investigação é constante, cabendo ao professor o papel de orientador. Os alunos retornam ao campo quantas vezes forem necessárias. A relação professor-aluno e aluno-aluno é ampliada pelas contínuas discussões e trocas de experiências.

Compiani (1991:14) considera que o campo pode ser um fio condutor para uma disciplina, propiciando, a partir de uma área de estudo, o entendimento dos principais processos e conceitos desta e o melhor desenvolvimento das peculiaridades da prática científica geológica, e dos respectivos procedimentos mentais. O autor considera que "o campo pode ser gerador de problemas, isto é, uma ótima situação de ensino problematizadora e, também, pode ser agente integrador da Geologia e outras Ciências na construção de uma visão abrangente de natureza".

Como exemplo desse processo gerador de problemas, pode-se relatar uma das atividades de campo autônomas realizadas por um dos autores na disciplina de Geologia Introdutória, em que atua como docente $^{2}$. O trabalho é realizado no curso de Geografia, no $1^{\circ}$. ano de Licenciatura Plena. Os alunos são divididos em grupos, cabendo a cada grupo o estudo de um bem mineral em processo de explotação na região metropolitana de Curitiba ${ }^{3}$. Esse estudo exige a realização de trabalhos de campo, durante os quais os alunos percebem vários aspectos, desde os ligados exclusivamente ao bem mineral escolhido até aqueles relacionados ao impacto ambiental, bem como a influência sobre as populações circunvizinhas. Um exemplo desta atividade refere-se à equipe que, em 1999, pesquisou extração de areia.

Ao visitar alguns locais de extração, a equipe observou que, após a exaustão de alguns depósitos, estes eram abandonados pelas empresas concessionárias e, posteriormente, ocupados por grupos de

\section{Adalberto Scortegagna}

3 Esta proposta de atividade teve início em 1998 no curso de Especialização em Ensino de Geociências no Instituto de geociências da UNICAMP. Desde então este trabalho é realizado com os alunos da disciplina de Geologia Introdutória, no curso de Geografia da FACIAUSO. indigentes que os utilizavam para edificar suas moradias, gerando grave problema urbano. Além disso, provocavam sério problema ambiental, pois estes locais são áreas de proteção aos mananciais, o que evidenciou, também, falha do poder público.

Em nenhum momento houve hesitação dos alunos em analisar tanto o bem mineral em explotação quanto a ação antrópica e suas conseqüências. Percebeu-se que a análise, não só do bem mineral estudado, mas também do local de extração e a observação dos problemas ambientais gerados é que permitiram aos alunos a realização de um trabalho enriquecedor. Assim, a saída ao campo e a pesquisa de um recurso mineral constituíram o fio condutor do trabalho.

Seguindo os parâmetros adotados por Compiani \& Carneiro (1993) e buscando-se enquadrála nesta classificação, observa-se que a saída de campo autônoma, de acordo com os objetivos pretendidos, apresenta como características marcantes o aproveitamento dos conhecimentos geológicos prévios do aluno; a elaboração de dúvidas e questões; a estruturação de hipóteses e criação de conhecimento; reconhecimento de feições e fenômenos da natureza, além de desenvolvimento e exercício de habilidades.

A visão de ensino observada é a formativa, pois permite ao aluno interagir com o meio e vislumbrar a possibilidade de aquisição de novos conhecimentos. Com referência ao emprego elou questionamento de modelos científicos, percebe-se que estes não interferem no processo didático pretendido, pois não há controle por parte do professor; assim os alunos podem seguí-los ou questioná-los. O método de ensino pode ser caracterizado como não-dirigido, sendo o aluno o centro do processo, pois é quem irá resolver problemas, definindo, ele mesmo, os passos da investigação.

O professor poderá orientá-lo ao longo do processo, quando há retorno ao campo, ou no final, em sala de aula, quando o aluno perceberá os erros e acertos de seu trabalho, sob a ótica científica.

Quanto à lógica predominante no processo, percebe-se o predomínio da lógica do aprendiz, pois "tem origem na postura natural do estudante frente a situações inéditas" Compiani \& Carneiro (1993:94).

A saída de campo autônoma destaca-se pelo fato do aluno ir ao campo sem a presença do professor, trazendo suas anotações, amostras e imagens que serão trabalhadas em sala de aula. Além disso, apre- 
senta, em relação à saída do tipo investigativa, maior influência na elaboração de dúvidas e questões e no desenvolvimento e exercício de habilidades ${ }^{4}$.

A partir do conjunto de informações trazidas pelos alunos, as discussões se tornam enriquecidas e eles percebem que o seu conhecimento prévio, valorizado pelo professor, é utilizado na construção da própria prática científica.

"[...] é fundamental para o estudante essa noção de conhecimento como um construto da prática científica, do ir e vir à fonte de informaçoes, de testar, reformular, elaborar e adquirir a noção dos limites da produção científica; tudo isso contribui para desmitificar o conhecimento científico e o cientista". (Compiani 1991:13)

A saída de campo autônoma não pode servir como pretexto para o professor se ausentar do campo. Os trabalhos de campo com a presença e orientação do professor são importantes, pois o contato direto com o objeto a ser investigado e os desafios que surgem, ao longo do trabalho, são enriquecidos com sua presença.

A saída autônoma tem por objetivo promover constante investigação ao longo do curso, permitindo que os alunos, a partir dos temas que vão sendo abordados em sala de aula, tenham a possibilidade de fazer a inter-relação entre a teoria e sua aplicação no cotidiano de forma mais independente.

A participação de turmas do período noturno, constituídas usualmente por alunos que trabalham durante o dia, fica facilitada nesse tipo de trabalho porque os horários de pesquisa são escolhidos pelos próprios alunos.

Com o acréscimo da nova categoria proposta obtém-se a classificação dos trabalhos de campo apresentada na Figura 1.

\section{Considerações finais}

As possibilidades de o professor realizar atividades de campo são várias, cada qual com suas características didáticas e metodológicas. Os vários tipos de atividades apresentadas neste artigo apresentam alguns aspectos didáticos distintos entre si. Cabe ao professor, a partir das características encontradas em seus alunos e instituição onde atua,

4 Elaboração de dúvidas e questões e desenvolvimento e exercício de habilidades estão entre os seis objetivos das atividades na classificação de Compiani \& Carneiro. (1993). definir qual atividade de campo melhor se adapta as suas condições. Observa-se, porém, a necessidade de repensar o papel do professor e do aluno nas atividades práticas. Scortegagna (2001) constatou a preocupação dos professores da disciplina de Geologia Introdutória, nos cursos de Geografia no Estado do Paraná, em preservar o aluno do impacto do novo, mediante distribuição prévia de roteiros de campo detalhados. O autor observou também que a maioria dos professores entrevistados preocupava-se em reproduzir no campo o conteúdo visto em sala de aula, limitando assim as possibilidades dos alunos construírem seus próprios conhecimentos.

A categoria de campo autônoma proposta neste artigo teve origem em várias experiências, entre elas o trabalho realizado pelos autores no Curso de Especialização em Ensino de Geociências da Unicamp em 1998, além da necessidade de criar alternativas de campo para turmas noturnas, com grandes dificuldades em acompanhar as saídas nos finais de semana. Em acréscimo a um trabalho investigativo, esta atividade permite aos alunos elaborar dúvidas e questões, conferindo-lhes maior independência no campo.

\section{Referências}

Anguita, F. \& Ancochea, E. 1981. Práticas de campo: alternativas a la excursión tradicional. In: SIMPOSIO Nacional sobre Enseñanza de la Geología, Anais... Madrid: Univ. Complutense Madrid, p. 317-326.

Brañas, M.P. 1981. Experiencias sobre el trabajo de campo en la enseñanza de la Geologia en el bachirellato. In: SIMPOSIO Nacional sobre Enseñanza de la Geologia, 1, Madrid. Memorias. Madrid: Universidad de Madrid, p. 295-302.

Brañas, M.P.; Pardo, X.; Paz, D. 1988. Experiencias didácticas sobre el trabajo de campo en Geologia: una perspectiva interdisciplinar. In: Henares, Rev. Geología, Madrid, 2 : 395-405.

Brusi, D. 1992. Reflexiones en torno a la didactica de las salidas de campo en Geologia (I): aspectos metodológicos. In: SIMPOSIO SOBRE Enseñanza de la Geología, 7, Santiago de Compostela. Anais... Instituto de Ciências de Educación, Universidad Santiago de Compostela, p.363-389.

Coelho A.M.S. 1997. Para uma caracterização do raciocínio geográfico. Belo Horizonte: Instituto de Geociências, UFMG, 152p. (Dissertação, Mestrado em Geografia). 
Compiani, M. 1988. O fazer geologia com ênfase no campo na formação de professores de ciências para o $1^{\circ}$ grau $\left(5^{a}\right.$ a $8^{a}$ séries). Campinas: Faculdade de Educação, Universidade Estadual de Campinas. 238p. (Dissertação, Mestrado em Educação).

Compiani, M. 1991. A relevância das atividades de campo no ensino de geologia na formação de professores de ciências. Cadernos do IG/UNICAMP, Campinas, 1(2):2-25.

Compiani, M., Carneiro, C.D.R. 1993. Os papéis didáticos das excursões geológicas. Enseñanza de las Ciências de la Tierra, 1(2):90-98.

Compiani, M.; Gonçalves, P.W. 1984. Aspectos didáticos e metodológicos de uma experiência de introdução dos alunos às atividades de campo em geologia. In: SBG, Congresso Brasileiro de Geologia, 33. Anais... Rio de Janeiro, p. 5185-5197.

Cuello, A .1988. La geologia como área interdisciplinar. Henares, Revista de Geologia, (2):367- 387.

Fantinel, L.M. 2000. Práticas de campo em geologia introdutória: papel das atividades de campo no ensino de fundamentos de geologia do curso de geografia. Campinas: Instituto de Geociências, Universidade Estadual de Campinas. 124p. (Dissertação, Mestrado em Educação Aplicada às Geociências).

Morcillo, J.G.; Herrero, C.; Centeno, J.D; Anguita, Muños, F.; Ortega, O.; Sanchez, J. 1997. El seminario sobre metodologias en las prácticas de campo: Rascafria 96. Resultados y valoración. Ensenãnza de las Ciencias de la Tierra, Girona, 5(1): 69-76.

Morcillo, J.G.; Rodrigo, M; Centeno, J.D; Compiani, M. 1998. Caracterización de las prácticas de campo: justificación y primeros resultados de una escuesta al professorado. Ensenãnza de las Ciencias de la Tierra, Madrid, 6(3):242-248.

Newerla, V.B. 1997. Roteiros didáticos e o seu papel nos trabalhos de campos. IG/UNICAMP, 32p. Monografia apresentada na disciplina Práticas de Campo no ensino de Ciências Naturais.

Paschoale, C. 1984. Alice no país da geologia e o que ela encontrou lá. In: SBG, Congresso Brasileiro de Geologia, 33, Rio de Janeiro. Anais... Rio de Janeiro, 5:5242-5249

Scortegagna, A. 2001. Trabalhos de campo nas disciplinas de Geologia Introdutória: Cursos de Geografia no Estado do Paraná. Campinas. Instituto de Geociências, Universidade Estadual de Campinas. 122 p. (Dissertação, Mestrado em Educação Aplicada às Geociências).

Spencer, E.W. 1990. Introductory Geology with a field emphasis. Journal of Geological Education. 38 : 246-248. 